\title{
Suicide amongst the Inuit of Nunavut: An Exploration of Life Trajectories
}

\author{
William Affleck $1,2, *$, Eduardo Chachamovich ${ }^{1,3}$, Nadia Chawky ${ }^{3}$, Guy Beauchamp ${ }^{3}$, \\ Gustavo Turecki ${ }^{1,2,3}$ and Monique Séguin 2,3 (D) \\ 1 Department of Psychiatry, McGill University, Montréal, QC H3A 0G4, Canada; \\ eduardo.chachamovich@douglas.mcgill.ca (E.C.); gustavo.turecki@mcgill.ca (G.T.) \\ 2 Département de psychoéducation et psychologie, Université du Québec en Outaouais, Gatineau, \\ QC J9A 1L8, Canada \\ 3 McGill Group for Suicide Studies, Montréal, QC H3A 0G4, Canada; Nadia.chawky@gmail.com (N.C.); \\ yowawa95@gmail.com (G.B.); Monique.Seguin@uqo.ca (M.S.) \\ * Correspondence: william.affleck@mail.mcgill.ca
}

Received: 6 February 2020; Accepted: 5 March 2020; Published: 11 March 2020

\begin{abstract}
This article reports results of the life trajectories from 92 Inuit who died by suicide, matched for age and gender with 92 living-controls. A proxy-based procedure and semi-structured interviews with informants were conducted to obtain trajectories of developmental events occurring over the life course for suicide and community-matched controls. Results from this research indicate two different trajectories that differentiate the control-group from the suicide-group throughout the life course. Even though the number of suicide attempts are similar between both groups, the suicide-group had a more important burden of adversity, which seemed to create a cascading effect, leading to suicide.
\end{abstract}

Keywords: suicide; Inuit; life trajectory

\section{Introduction}

Inuit are a group of culturally similar Indigenous peoples inhabiting the Arctic regions of Greenland, Canada, and the United States. Approximately 65,000 Inuit live in Canada. Of these, the majority live in the Inuit homeland of Inuit Nunangat, which is comprised of four Inuit regions: Nunavut, Nunavik, Nunatsiavut, and the Inuvialuit Settlement Region [1].

Inuit in Canada currently suffer from one of the highest rates of suicide in the world [2-4]. Rates range from five to 25 times the Canadian average. In the five-year period, from 2009-2013, Canada's suicide rate was 11 per 100,000. In Inuit Nunangat, rates ranged from 60 per 100,000 in the Inuvialuit Settlement Region to 275 per 100,000 in Nunatsiavut [5]. Rates are highest for young Inuit men, who are 40 times more likely to die by suicide than their peers in Southern Canada [6].

Theories of suicide have converged to identify major risk factors implicated in the complex etiology of suicide [7]. Models suggest that distal predisposing variables (i.e., temperament and genetics) and developmental variables (i.e., early adversity and cognitive style) impact upon proximal or precipitating factors, such as mental health problems and substance abuse, which when coupled with recent life events, can increase vulnerability to suicide [8-15].

In Western populations, theories of suicide are most often based on individual suffering, as opposed to Indigenous populations, where suicide is largely considered as social suffering [16]. Research on Indigenous populations, including the Inuit, has tended to focus on larger systemic factors that resulted from colonization to account for the high rates of suicide [17]. From this perspective, suicide is viewed not only as an individual problem but also as an outcome of socioeconomic marginalization; loss of 
culture and language; and government policies and practices that separated families and forced assimilation through residential schools, where widespread abuse and violence had profound effects on individuals and communities [18-25]. Identified risk factors for suicide amongst the Inuit reflect this understanding, and they include historical trauma, social iniquities, intergenerational trauma, the loss of culture and language, and mental distress and illness [4].

Developmental research has introduced the concept of cumulative advantage/disadvantage, suggesting that early life events pave the road to an individual's future health and well-being [26,27]. The presence of early adversities related to family structure, abuse and trauma, and relational and social difficulties may have distinct long-term effects because they impede on an individual's development in different domains, such as interpersonal, social, professional, and health issues [28,29].

Our research group has been using a life course approach to identify different pathways leading toward and away from suicide [30,31]. In an earlier study, we outlined the role that protective factors play in the prevention of suicide for Inuit across the life course [32]. To our knowledge, no other study has investigated the sequence of life events and the different developmental experiences of Inuit peoples. The current study investigated individual trajectories in order to identify the presence and chronology of major adversity in the lives of Inuit in Nunavut (suicide and living control). A better understanding of the interaction between individual vulnerabilities and contextual or environmental risk factors can aid policy makers in developing targeted suicide-prevention interventions.

\section{Materials and Method}

\subsection{Qaujivallianiq Inuusirijauvalauqtunik ("Learning from Lives that have been Lived")}

From 2005 to 2010, a large follow-back study on suicide, an age- and gender-matched case-control study, was conducted among the Inuit of Nunavut by investigating all suicide cases that occurred in the territory between 2003 and 2006 [33,34]. Living-controls were selected from the Nunavut Health Care Registration File. For each suicide, the researchers randomly selected a community control that matched on gender and age. The study used two different types of interviews, both using a proxy-based interview procedure to gather information on mental health problems, life events, protective factors, and adversities: First, we used the psychological autopsy method, which consists of interviewing close relatives and/or friends of the deceased, using a combination of open-ended questions and standardized instruments to gather information on the deceased [35]. Second, we used the life calendar trajectory method, an interview technique in which life events are mapped onto different developmental spheres of an individual's life trajectory [31].

From the initial 240 clinical vignettes completed by the research team for data on mental health problems, 92 suicide cases had sufficient information to analyze the life trajectory. This study reports on the life trajectory of these 92 suicide cases and 92 matched living-controls. The number of informants necessary to complete the interview was determined by the interviewer, based on the quality of the interviews and the amount of information gathered. For this study, 186 interviews were conducted for suicide cases (mean of 2 interviews per case), and 148 interviews for controls (mean of 1.6 interview per case) were carried out. Respondents for the suicide group and controls respectively were parents ( 54 vs. 42 ), partners (19 vs. 28 ), siblings ( 29 vs. 40 ), extended family members (43 vs. 15 ), friends (35 vs. 23), and professionals (6 vs. 0) for the suicide group and controls, respectively. All interviews were conducted in English or Inuktitut, according to the respondent's preference. Medical charts, coroner's notes, and criminal records were also systematically reviewed.

The Institutional Research Ethics Board (REB) of the Douglas Mental Health University Institute approved the study, and the Nunavut Research Institute issued a research license. The project was developed in partnership with community organizations in Nunavut, including the regional suicide prevention organization, the Embrace Life Council and Nunavut Tunngavik Incorporated (NTI) [34]. Results from this study were presented to stakeholders and community members before publication, as required by chapter 9 of the second edition of the Tri-Council Policy Statement: Ethical conduct for 
Research Involving Humans [36]. The first author met on numerous occasions with representatives of NTI in Iqaluit, Nunavut, who approved both the results and the language used in the article.

\subsection{Life-Trajectory Methodology}

The life calendar method was embedded in the larger study $[33,34]$. The current paper focuses on results from the life-trajectory interviews, which investigated the occurrence of life events and the cumulative burden of adversity over the life course. This interview method, which has been described elsewhere [30,31], uses a life trajectory calendar to reconstruct the major events of an individual's life.

The interview uses a narrative approach in order to elicit information relevant to understand the context in which the significant life events occurred. Each life event may be perceived differently and may have different consequences depending on the circumstances in which it takes place. For example, birth, adoption, and marriage may have distinct consequences depending on the culture and the individual contexts in which they occur [37]. Some events, like custom adoption, which is common in Inuit culture, may have specific consequences for the individual and others in their social environment [38]. Using a context-sensitive method of inquiry helps establish a distinction between events, especially in light of different cultural norms. The different life spheres discussed during the life-trajectory interview were as follows: circumstances of death (method, motivation, and intoxication by alcohol/drugs); place of residence and housing; experiences during childhood and adolescence; interpersonal and romantic relationships; relations with friends; school and academic experiences; professional experiences; legal problems; family history of suicide and other family adversities; personal difficulties and mental health problems; and mental health services received.

The interviews started with general questions, such as the following: "Could you tell me how (name of case or control) was as a child?" and "Could you tell me about (name's) school attendance?" Interviewers would then probe further and ask detailed questions to verify if particular events happened or not in specific spheres of the individual's life course. Each sphere included a number of variables that were important to investigate. Since more than one informant was interviewed, the multiple narrative accounts from different perspectives enriched the information pertaining to the occurrence and the context of each life event. Using this narrative methodology [38], interviewers sought to accumulate sufficient details about the individual's life events and its trajectory to allow trained evaluators to assess the key characteristics of each event, for example, duration, severity, and frequency.

\subsection{Psychological Autopsy Method}

Mental health and personality disorders were assessed by administering the Structured Clinical Interview for DSM-IV Axis I and Axis II [39,40]. These results have already been reported [33]. In this paper, we report the age in which mental health disorders occurred and their durations.

\subsection{Sociodemographic Variables}

Finally, sociodemographic variables were assessed by using standardized instruments culturally adapted to Nunavut [33].

\subsection{Procedure and Analysis}

The first step was to identify and code each event, the age period, and its duration in a graphic calendar. When the interviews with participants were completed, clinical case histories (case vignettes) were drafted with the information obtained from all the measurements and submitted to the panel of evaluators who were independent from the interviewers. The panel was composed of researchers from our team, clinical practitioners, and psychologists who analyzed the life trajectories and established a summary variable identified as the "overall contextual burden of adversity rating" for every 5-year interval of the life trajectory. The evaluators assessed the "contextual burden" of events by assessing their relative weight within the respondent's developmental circumstances. This conceptualization of 
contextual burden was borrowed from the morbidity burden or low disease burden approach used to identify the overall morbidity that affects health. It is associated with allostatic load, a concept that links psychosocial stress with the neurobiological and genetic dimensions of mental disorders and suicide. The overall burden assessments ranged from severe (rating of 5 or 6 ) to moderate (3 or 4 ) to low (1 or 2). Case reference logs were written and used to maintain the same evaluation across all cases. For all cases, the evaluators coded the burden of adversity for each 5-year period independently before reaching a consensus through discussion. In previous studies from our research group, the intra-pair agreement for each 5-year segment ranged from $76 \%$ to $97 \%$; the lowest agreement was found in the 0-to-4-year's age segment.

The second step was to study the burden of adversity over time. Combined Discrete Time Survival (DTS) and Growth Modeling (GM), using the software Mplus Version 7.4 for Mac [41], were used to examine the individual variation in burden of adversity within age periods ( $0-4$ years through to 45-49 years) for control and suicide cases in a multigroup analysis. GM can identify distinct sets of continuous growth factors, which are indicated by the intercept, slope, and quadratic term. Suicide is considered as a unique event in time, and in that respect, DTS analysis (generating proportional odds continuous latent variable) was added to the GM. The complete statistical model is illustrated in Figure 1. The objective of this method of analysis was to examine the pattern of variation and stability over time for each group.

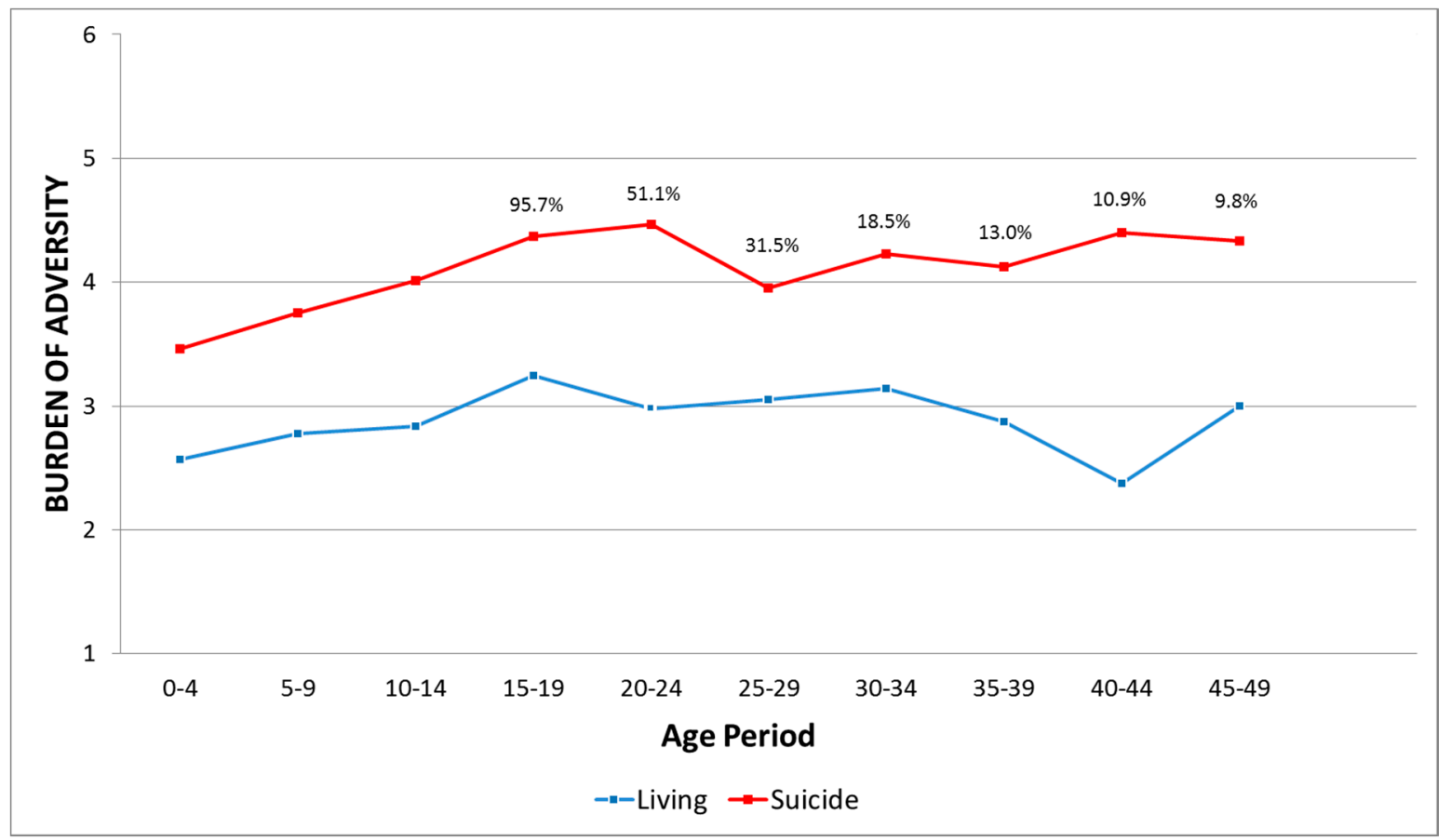

Figure 1. Trajectories of control-group and suicide cases. The \% corresponds to the proportion of serving individuals on entry of the age period for the suicide group.

The third step was identifying the presence of cumulative adversity and pathways to suicide. Each life calendar was analyzed individually, and the number of events in each 5-year age period was recorded. Based on clinical vignettes, we organized the data into four different life spheres: (1) early adversity of maltreatment; (2) household and family dysfunction; (3) personal/mental health difficulties; and (4) social difficulties. In each sphere, we grouped a number of variables that were identified by respondents during the interview process. Early adversity of maltreatment included four variables: familial sexual abuse, sexual violence, physical violence, and psychological violence. The sphere of household and family dysfunction included the possible presence of 16 variables: incoherent rules, lack of discipline, lack of supervision, tension with parents, negligence, role reversal, affective distance, 
family secrets, parental separation, parental divorce, parental mental health difficulties, witnessing parental violence, living with someone who misused alcohol, tension with sibling, food insecurity, and adverse housing conditions. Personal/mental health difficulties included the possible presence of nine variables: Axis I diagnosis (depression, anxiety, gambling, and schizophrenia), alcohol and drug abuse, personality disorder, number of suicide attempts, self-harm, and psychiatric hospitalization. Social difficulties included the possible presence of five variables: conflict with peers, social isolation, bad influence from peers resulting in legal problems, separation or loss of a friend, and difficulty in romantic relationship or commitment.

\section{Results}

\subsection{Sociodemographic}

A total of 184 life calendars were analyzed: 92 pairs (suicide and living controls) matched for date of birth and gender (14 women in each group). Analysis of the sociodemographic data identified differences between the two groups. Individuals in the living control group were on average older (Mean Age $=27.8, S D=9.0)$ than the suicide group (Mean Age $=23.2, S D=9.0)(t(182)=3.48)$. Results indicate that $49 \%$ of individuals in the suicide group died before 20 years of age; by 25 years of age, $68.5 \%$ had died, and by 30 years of age, $81.5 \%$ had died. Reflecting the group difference, there was a greater proportion of living controls with a married status $(46.7 \% \mathrm{vs} .25 .0 \%$, chi-square $=8.5$, $p<0.005)$, and a job (66.3\% vs. $35.9 \%$, chi-square $=15.9, p<0.001)$. There was a significantly greater proportion of individuals with a high school diploma in the control group compared to the suicide group $(23(25.0 \%)$ vs. $6(6.5 \%)$, chi-square $=10.5, p<0.005)$.

\subsection{Comparison between Group Trajectories}

The longitudinal burden of adversity (summary variable) data were analyzed in order to compare the global burden of adversity of each group, for every five-year period. The shape of the two trajectories and their continuous growth factors (Figure 1) exhibited two different trajectories pertaining to suicide or living controls. The $x$-axis corresponds to the age period and the $y$-axis to the burden of adversity (low burden 1 or 2 ; moderate burden 3 or 4 ; and high burden 5 or 6 ). Based on this figure, both groups have a somewhat parallel but distinct burden of adversity throughout their lives. Individuals in the living control group were essentially exposed to overall moderate adversity, which slightly increased over time (Table 1, significant linear term). The significance of the quadratic terms is due to the increase in the burden of adversity taking place in the 40 to 44 age period for this group. Individuals in the suicide group had a larger overall burden of adversity score during their lifetime, varying from moderate to severe, whereas the most severe period was between 14 and 25 years, with a slightly descending overall burden after 25 years (Table 1).

Table 1. Trajectory parameters.

\begin{tabular}{ccc}
\hline & Living & Suicide \\
\hline Percentage of sample & $50.0 \%$ & $50.0 \%$ \\
\hline Parameters, means (SE) & & \\
Intercept & $2.857(0.122)^{* * *}$ & $4.077(0.118)^{* * *}$ \\
Linear change & $0.261(0.078)^{* * *}$ & $0.324(0.110)^{* *}$ \\
Quadratic change & $0.046(0.016)^{* *}$ & $0.022(0.024) \mathrm{NS}$ \\
\hline
\end{tabular}

These two different trajectories in regard to the burden of adversity are carried out throughout the life course. Results of the presence of early maltreatment during the five-to-nine age period indicated that $33.7 \%$ of children in the suicide group were subjected to one, two, or three types of violence during the five-to-nine age period, compared to $17.4 \%$ in the control group (Table 2). However, 
psychological violence was the only significant variable between the suicide group and the control group $(20.7 \%$ vs. $7.6 \%)$.

Table 2. Early maltreatment: types and number of abuse among groups in the five-to-nine age period.

\begin{tabular}{|c|c|c|c|c|c|c|c|c|}
\hline \multirow[b]{3}{*}{ Suicide group } & \multicolumn{4}{|c|}{ Type of Abuse } & \multicolumn{4}{|c|}{ Number of Abuse } \\
\hline & Physical & Sexual & Psychologic & l Incest & 0 & 1 & 2 & 3 \\
\hline & $16(17.4 \%)$ & $2(2.2 \%)$ & $\begin{array}{c}19 \\
(20.7 \%) *\end{array}$ & $6(6.5 \%)$ & $61(66.3 \%)$ & $21(22.8 \%)$ & $8(8.7 \%)$ & $2(2.2 \%)$ \\
\hline Living & $12(13.0 \%)$ & $3(3.3 \%)$ & $7(7.6 \%) *$ & $0(0.0 \%)$ & $76(82.6 \%)$ & $10(10.9 \%)$ & $6(6.5 \%)$ & $0(0.0 \%)$ \\
\hline
\end{tabular}

${ }^{*} p<0.05 . \phi$ (phi) value for the psychological abuse difference $=0.19$.

As for the number of events present for each sphere, all demonstrate significant results (Table 3). The data indicate how many events were present in the lives of individuals, in both groups, and the zero $\%$ gives the proportion of individuals who were not exposed to any events registered to a specific sphere. For example, results for the first sphere, early adversity of maltreatment, indicate that $66 \%$ of individuals who died by suicide were not subjected to early maltreatment and violence, compared to $78 \%$ in the living-control group. In the second sphere, household and family dysfunction, $14 \%$ of individuals from the suicide group were not exposed to any adversities, compared to $33 \%$ for living-controls. As for the third sphere, personal and mental health difficulties, 53\% of those in the suicide group were not exposed to personal difficulties (mental health and substance misuse) during the 10-14 age-year period, compared to $83 \%$ of the control group. Finally, in the sphere of social difficulties, $75 \%$ of individuals in the suicide group were not exposed to social difficulties during the 15-19 age period, compared to $89 \%$ of the control-group. Thus, there were significant differences between groups in all four spheres.

Table 3. Number of variables present for each sphere: comparison between groups.

\begin{tabular}{|c|c|c|c|c|c|c|c|}
\hline \multirow[b]{2}{*}{ Sphere } & \multirow[b]{2}{*}{ Themes } & \multirow[b]{2}{*}{$\mathrm{Nb}$ Items } & \multicolumn{2}{|c|}{ Suicide } & \multicolumn{2}{|c|}{ Living } & \multirow[b]{2}{*}{$p(\phi)$} \\
\hline & & & $\begin{array}{l}\text { Maximum } \\
\text { Count }\end{array}$ & $\%$ Zero & $\begin{array}{l}\text { Maximum } \\
\text { Count }\end{array}$ & $\%$ Zero & \\
\hline $\begin{array}{l}\text { Early adversity of } \\
\text { maltreatment }\end{array}$ & $\begin{array}{l}\text { Subjected to sexual, physical } \\
\text { or psychological violence * }\end{array}$ & 4 & 3 & 66.3 & 2 & 82.6 & $\begin{array}{l}<0.05 \\
(0.19)\end{array}$ \\
\hline $\begin{array}{l}\text { Household and } \\
\text { family Dysfunction }\end{array}$ & $\begin{array}{l}\text { Conflictual or dysfunctional } \\
\text { family environment }\end{array}$ & 17 & 8 & 14.1 & 7 & 32.6 & $\begin{array}{l}<0.01 \\
(0.22)\end{array}$ \\
\hline $\begin{array}{l}\text { Personal/mental } \\
\text { health difficulties }\end{array}$ & Mental health problems $* * *$ & 9 & 3 & 53.3 & 3 & 82.6 & $\begin{array}{l}<0.01 \\
(0.31)\end{array}$ \\
\hline Social difficulties & $\begin{array}{c}\text { Conflicts with peers, } \\
\text { isolation, bad influence } \\
\text { **** }\end{array}$ & 5 & 5 & 75.0 & 5 & 89.1 & $\begin{array}{l}<0.05 \\
(0.18)\end{array}$ \\
\hline
\end{tabular}

* Early adversity of maltreatment included variables such as incest, sexual violence, physical violence, and psychological violence. ${ }^{* *}$ Household and family dysfunction included variables such as incoherent rules, tension, lack of discipline, negligence, role reversal, affective distance, family secrets, parental separation, parental divorce, parental mental health difficulties, witnessing parental violence, living with someone who misuse alcohol, tension with sibling, overcrowding, lack of supplies, difficult housing conditions, food shortage, etc. ${ }^{* *}$ Personal/mental health difficulties included variables such as Axis I diagnosis, personality disorder, alcohol and drug abuse, number of suicide attempts, other problems of mental health, and psychiatric hospitalization. **** Social difficulties included variables such as conflict with peers, social isolation, bad influence from peers, resulting in legal problems, separation or loss of a friend, and difficulty in relationship commitment. $\Phi$ is the phi value.

The data of all Axis I diagnosis were merged together at age 5-9, 10-14, and 15-19, and Axis II diagnosis was merged after 19, in order to determine the importance of this variable on suicide (see Table 4). Alcohol and drug abuse were included as a specific disorder-and not added in Axis Ibecause it was significant by itself, especially after 10 years of age. Results show that the prevalence of mental health problems was greater for those in the suicide group compared to those in the control group during the 10-to-14 age period with regard to Axis I disorders and alcohol and drug abuse. For the 15-to-19 age period, the suicide group had significantly more Axis I disorders and Axis II disorders, as well as alcohol and drug abuse. Of note, the number of suicide attempts was not significantly different between groups and age periods. 
Table 4. Diagnoses and suicide attempts by age and groups.

\begin{tabular}{|c|c|c|c|c|c|c|c|c|c|c|}
\hline & \multicolumn{2}{|c|}{$\begin{array}{c}\text { Total } \\
(n \text { Initial = 184) }\end{array}$} & \multicolumn{2}{|c|}{$\begin{array}{c}\text { Living } \\
(n=92)\end{array}$} & \multicolumn{2}{|c|}{$\begin{array}{c}\text { Suicide } \\
\text { ( } n \text { Initial = 92) }\end{array}$} & \multirow[t]{2}{*}{$\chi^{2}(\phi)$} & \multirow[t]{2}{*}{ OR } & \multirow[t]{2}{*}{ CI95\% } & \multirow[t]{2}{*}{$p$} \\
\hline & $\begin{array}{c}n / n \\
\text { Alive }\end{array}$ & $\%$ & $n$ & $\%$ & $\begin{array}{c}n / n \\
\text { Alive }\end{array}$ & $\%$ & & & & \\
\hline Axis I (5-9 years) & $8 / 184$ & 4.34 & 2 & 2.17 & $6 / 92$ & 6.52 & - & - & - & NS \\
\hline Axis I (10-14 years) & $25 / 181$ & 13.8 & 3 & 3.26 & $22 / 89$ & 24.7 & $\begin{array}{c}17.5 \\
(0.31)\end{array}$ & 9.7 & $3.2-38$ & $<0.001$ \\
\hline Axis I (15-19 years) & $77 / 149$ & 50.3 & 20 & 21.7 & $55 / 57$ & 96.5 & $\begin{array}{c}78.7 \\
(0.73)\end{array}$ & 99 & $23-448$ & $<0.001$ \\
\hline Axis II (5-9 years) & $0 / 184$ & 0 & 0 & 0 & $0 / 92$ & 0 & - & - & - & NS \\
\hline Axis II (10-14 years) & $3 / 181$ & 1.65 & 0 & 0 & $3 / 89$ & 3.37 & - & - & - & NS \\
\hline Axis II (15-19 years) & $19 / 149$ & 12.8 & 4 & 4.34 & $15 / 57$ & 26.3 & $\begin{array}{c}15.3 \\
(0.32)\end{array}$ & 7.8 & $12-28$ & $<0.001$ \\
\hline $\begin{array}{l}\text { Alcohol/Drug abuse } \\
\text { (5-9 years) }\end{array}$ & $6 / 184$ & 3.26 & 2 & 2.17 & $4 / 92$ & 4.35 & - & - & - & NS \\
\hline $\begin{array}{l}\text { Alcohol/Drug abuse } \\
\text { (10-14 years) }\end{array}$ & $35 / 181$ & 18.8 & 9 & 9.78 & $25 / 89$ & 28.1 & $\begin{array}{c}9.9 \\
(0.23)\end{array}$ & 3.6 & $1.6-8.1$ & $<0.005$ \\
\hline $\begin{array}{l}\text { Alcohol/Drug abuse } \\
\text { (15-19 years) }\end{array}$ & $82 / 149$ & 51.7 & 34 & 37.1 & $43 / 57$ & 75.4 & $\begin{array}{l}20.9 \\
(0.37)\end{array}$ & 5.2 & $2.4-10$ & $<0.001$ \\
\hline \multicolumn{11}{|l|}{$\begin{array}{c}\text { Number of suicide } \\
\text { attempts }\end{array}$} \\
\hline 0 & 111 & $60.3 \%$ & 58 & $63.0 \%$ & 53 & $57.6 \%$ & - & - & - & NS \\
\hline 1 & 35 & $19.0 \%$ & 17 & $18.5 \%$ & 18 & $19.6 \%$ & - & - & - & NS \\
\hline 2 & 14 & $7.6 \%$ & 5 & $5.4 \%$ & 9 & $9.8 \%$ & - & - & - & NS \\
\hline $3+$ & 24 & $13.0 \%$ & 12 & $13.0 \%$ & 12 & $13.0 \%$ & - & - & - & NS \\
\hline
\end{tabular}

$(\phi)$ Corresponds to the phi value.

Even though the results were not significant, both groups were exposed to antecedents of suicide death: $26 \%$ of individuals in the suicide group and $17 \%$ of the control group had histories of suicide among first-degree family members. However, when we cumulate number of first-degree family members, extended family members, and friends, $56 \%$ of the suicide group were exposed to one to three suicide deaths, and $8.6 \%$ were exposed to between four and nine suicides. As for the control group, $65 \%$ were exposed to one to three suicide deaths, and $5.5 \%$ were exposed to between four and nine suicides in their lifetime (Table 5).

Table 5. History of suicide completion among first-degree family members and friends.

\begin{tabular}{|c|c|c|c|c|c|c|}
\hline \multirow[b]{2}{*}{$\begin{array}{l}\text { History of Suicide } \\
\text { Completion }\end{array}$} & \multicolumn{2}{|c|}{$\begin{array}{l}\text { First-Degree Family } \\
\text { Member(s) }\end{array}$} & \multirow[t]{2}{*}{$n$} & \multicolumn{3}{|c|}{$\begin{array}{l}\text { Cumulative Numbers of First-Degree, } \\
\text { Extended Family Member(s) and Friend(s) }\end{array}$} \\
\hline & 0 & 1 to 3 & & 0 & 1 to 3 & 4 to 9 \\
\hline Suicide group & 68 (73.9\%) & $24(26.1 \%)$ & 92 & $32(34.8 \%)$ & $52(56.6 \%)$ & $8(8.6 \%)$ \\
\hline Living & $76(82.6 \%)$ & $16(17.4 \%)$ & 92 & $27(29.3 \%)$ & $60(65.2 \%)$ & $5(5.5 \%)$ \\
\hline
\end{tabular}

\section{Discussion}

Results from this study indicate significant differences between living-control and suicides-cases, resulting in a lower burden of adversity among the control-group throughout the life course. Though the control-group was exposed to adversities, they were not exposed to the severity of adversity compared to the suicide-group. In a recent study from our research group with the same participants [32], findings demonstrated that people with no suicide attempt had more protective variables throughout their lifespan than people who died by suicide. More specifically, the protective factors offered by the social environment show the greatest difference, indicating that universal strategies that could have an impact on increasing community connectedness and stability may have a positive impact on individual suicide vulnerability.

As for people included in the suicide group, they were significantly more exposed to early adversity and were exposed to a higher level of adversity in different spheres of life (e.g., early adversity, 
family environment, personal and mental health sphere, social sphere, etc.). Early adversity, such as psychological and physical violence and household dysfunction during early childhood, may impact on the future course of development and promote the emergence of additional problems that can contribute to vulnerability to suicide, including aggressiveness, impulsivity, behavior dysregulation, inefficient coping styles [42,43], poor attachment skills [44], and lack of personal control or mastery over their lives [45]. This observation has been abundantly confirmed in many fields and in research conducted with many different populations in the last few decades [30,46-50].

Results from this study report that $86 \%$ of individuals in the suicide group were exposed to at least one adverse household and family experience, compared to $67 \%$ of individuals of the control group. The cumulative effect of adverse events may have an impact on the overall burden of adversity and lead to suicide vulnerability over time. The epidemiological ACE (Adverse Childhood Experience) study in the US population [51] showed that the likelihood of suicide attempt was found to be more than 12 times greater for those who had four ACEs than for those who reported no adverse childhood experiences. This developmental pattern suggests that early adversity (e.g., being witness to family tension and violence, parental mental health problems, neglect, intimidation, etc.) coupled with socioeconomic disadvantage (e.g., overcrowding and food insecurity in the household), represents an important risk factor for a cascading effect leading to the presence of early mental health difficulties, such as alcohol and substance abuse in young adolescents, and eventually social and relational problems contributing to suicide vulnerability. Our findings affirm the importance of selective interventions targeting children, youth, and young adults who are exposed to violence and/or psychologically dysfunctional households.

\section{Limitations}

One important limitation is the possible lack of cultural perspective. There is a long and painful history of research focusing upon the individual and social deficits in Canadian Inuit culture and society. Along with other aspects of the colonial enterprise, this research may contribute to inaccurate beliefs about Inuit culture in the dominant society and undermine the pride that Inuit have in their culture and heritage [52]. This limitation can also deflect attention from the many positive individual, environmental, and social forces within Inuit culture and society, which have been found to help protect against suicide [32]. When considering the current study, readers should keep in mind that the strength, resilience, and adaptability of Inuit far outweigh the vulnerabilities discussed in this article, as witnessed by the tremendous advancements that have been made in the face of great historical and contemporary disadvantage.

Other limitations relate to the use of the retrospective method. First, the reliability of recall of events is uncertain. Although every effort was made to maximize the accuracy of the retrospective reports and construct an accurate timeline, there may have been important events that close relatives or friends were not privy to. A large number of variables were tested as potential predictors, but robust statistical methods were used to ensure statistical validity. Worth noting is the effort made throughout this methodology to maximize the accuracy of retrospective reports and effectively record the timeline of events and the onset of mental health problems. Although the narrative methodology has limitations, it is consistent with the way in which personal memory is organized and, hence, more likely to elicit potential causal factors than methods that elicit facts in isolation.

Lastly, with the exception of substance abuse disorder, mental health problems were not described in detail, except to identify the age period in which the participant acknowledged the difficulties started. The small number of participants made it difficult to find statistical significance between age period and type of disorders. However, the analysis did show the burden of mental health problems and alcohol and drug abuse on suicide vulnerability. Axis I and Axis II disorders could be a factor in suicide vulnerability and should be considered in greater depth in future research. 


\section{Conclusions}

This is the first case-control study to trace the life trajectories of Inuit in Nunavut who died by suicide. Our results clearly indicate a heavier burden of adversity among individuals who died by suicide, starting early in life and creating a cascade of risk. While results indicate that the types of risk factors are similar to those found in literature on suicide, the overall burden of adversity for Inuit is more important and may result from different sources, such as the many historical and contemporary traumas that resulted from colonization. It is important to note that the load of the risk factors stemmed from determinants of health factors, such as overcrowded housing and food insecurity. Such factors can create stress, tensions, and difficulties in parental relations and parental roles, resulting in children being exposed to higher levels of adversity within the household. Taking action to improve the conditions of daily life during early childhood and school age would provide upstream opportunities, both to improve the population's mental health and to reduce the risk of suicide.

Author Contributions: M.S. conceived of and designed the study and developed the grid used to identify adverse life events; M.S. and N.C. performed the coding and panels; M.S. and G.B. analyzed that data; E.C. and G.T. provided the initial data from their study; W.A. wrote the article and consulted with local partners in Nunavut. M.S., N.C., E.C., and G.T. reviewed the article. All authors have read and agreed to the published version of the manuscript.

Funding: This research was funded by the Canadian Institute of Health Research-New Emerging Team grant (SAN-73555). This research was supported by the Reseau Québécois sur le suicide, les troubles de l'humeur et les troubles associés, funded by the FRSQ, and CIHR Pathways to Health Equity Suicide Prevention Implementation Research Team Grant (L. J. Kirmayer, PI).

Acknowledgments: It is important to acknowledge the participation of families and friends who took the time to remember their loved ones by sharing their stories and memories and who hope their efforts will help in suicide prevention. Special thanks to Jean Allen, Senior Research Advisor for Nunavut Tunngavik Incorporated (NTI), for her feedback and support of this project.

Conflicts of Interest: The authors declare no conflict of interest.

\section{References}

1. Inuit Tapiriit Kanatami (ITK) Inuit Statistical Profile 2018. Available online: https://www.itk.ca/wp-content/ uploads/2018/08/Inuit-Statistical-Profile.pdf (accessed on 26 February 2020).

2. Bjerregaard, P.; Young, T.K.; Dewailly, E.; Ebbesson, S. Indigenous health in the Arctic: An overview of the circumpolar Inuit population. Scand. J. Public Health 2004, 32, 390-395. [CrossRef] [PubMed]

3. Boothroyd, L.J.; Kirmayer, L.J; Spreng, S.; Malus, M.; Hodgins, S. Completed suicides among the Inuit of northern Quebec, 1982-1996: A case-control study. CMAJ 2001, 165, 749-755. [PubMed]

4. Kirmayer, L.J.; Brass, G.; Holton, T.; Paul, K.; Simpson, C.; Tait, C. Suicide among Aboriginal People in Canada; Aboriginal Healing Foundation: Ottawa, ON, Canada, 2007.

5. Inuit Tapiriit Kanatami (ITK). National Inuit Strategy on Suicide. Available online: https://www.itk.ca/wpcontent/uploads/2018/04/ITK_NISR-Report_English_low_res.pdf (accessed on 26 February 2020).

6. Nunavut Suicides by Region, Sex, Age Group and Ethnicity, 1999 to 2009. Available online: http://www.eia. gov.nu.ca/stats/historical.html (accessed on 26 February 2020).

7. Turecki, G.; Brent, D. Suicide and suicidal behaviour. Lancet 2016, 387, 1227-1239. [CrossRef]

8. Arsenault-Lapierre, G.; Kim, C.; Turecki, G. Psychiatric diagnoses in 3275 suicides: A meta-analysis. BMC Psychiatry 2004, 4, 37. [CrossRef] [PubMed]

9. Barraclough, B.; Bunch, J.; Nelson, B.; Sainsbury, P. A hundred cases of suicide: Clinical aspects. Br. J. Psychiatry 1974, 125, 355-373. [CrossRef]

10. Dumais, A.; Lesage, A.D.; Alda, M.; Rouleau, G.; Dumont, M.; Chawky, N.; Roy, M.; Mann, J.J; Benkelfat, C.; Turecki, G. Risk factors for suicide completion in major depression: A case-control study of impulsive and aggressive behaviors in men. Am. J. Psychiatry 2005, 162, 2116-2124. [CrossRef]

11. Joiner, T. Why People Die by Suicide; Harvard University Press: Cambridge, MA, USA, 2007.

12. Kim, C.D.; Lesage, A.; Seguin, M.; Chawky, N.; Vanier, C.; Lipp, O.; Turecki, G. Patterns of comorbidity in male suicide completers. Psychol. Med. 2003, 33, 1299-1309. [CrossRef] 
13. McGirr, A.; Alda, M.; Seguin, M.; Cabot, S.; Lesage, A.; Turecki, G. Familial aggregation of suicide explained by cluster $\mathrm{B}$ traits: A three-group family study of suicide controlling for major depressive disorder. Am. J. Psychiatry 2009, 66, 1124-1134. [CrossRef]

14. Nock, M.K.; Hwang, I.; Sampson, N.; Kessler, R.C.; Angermeyer, M.; Beautrais, A.; Borges, G.; Bromet, E.; Bruffaerts, R.; De Graaf, R.; et al. Cross-national analysis of the associations among mental disorders and suicidal behavior: Findings from the WHO World Mental Health Surveys. PLoS Med. 2009, 6, e1000123. [CrossRef]

15. Rudd, M.D. Fluid Vulnerability Theory: A Cognitive Approach to Understanding the Process of Acute and Chronic Suicide Risk. In Cognition and Suicide: Theory, Research, and Therapy; Ellis, T.E., Ed.; American Psychological Association: Washington, DC, USA, 2006; pp. 355-367.

16. Wexler, L.M.; Gone, J.P. Culturally Responsive Suicide Prevention in Indigenous Communities: Unexamined Assumptions and New Possibilities. Am. J. Public Health 2012, 102, 800-806. [CrossRef]

17. Morris, M.; Crooks, C. Structural and cultural factors in suicide prevention: The contrast between mainstream and Inuit approaches to understanding and preventing suicide. J. Soc. Work Place 2015, 29, 321-338. [CrossRef]

18. Alexander, J.C. Toward a theory of cultural trauma. In Cultural Trauma and Collective Identity; Alexander, C.J., Ed.; University California Press: Berkeley, CA, USA, 2004; pp. 1-30.

19. Bombay, A.; Matheson, K.; Anisman, H. The impact of stressors on second generation Indian residential school survivors. Transcult. Psychiatry 2011, 48, 367-391. [CrossRef] [PubMed]

20. Chandler, M.J.; Lalonde, C.E. Cultural Continuity as a hedge against suicide in Canada's First Nation. Transcult. Psychiatry 1998, 35, 220-221. [CrossRef]

21. Elias, B.; Mignne, J.; Hall, M.; Hong, S.; Hart, L.; Sareen, J. Trauma and suicide behaviour histories among a Canadian indigenous population: An empirical exploration of the potential role of Canada's residential school system. Soc. Sci. Med. 2012, 74, 1560-1569. [CrossRef] [PubMed]

22. Kral, M.J. Postcolonial suicide among Inuit in Artic Canada. Cult. Med. Psychiatry 2012, 36, $306-325$. [CrossRef] [PubMed]

23. Kral, M.; Idlout, L.; Minore, J.B.; Dyck, R.; Kirmayer, L.J. Unikkaartuit: Meanings and experiences of suicide among Inuit in Nunavut, Canada. Int. J. Indig. Health 2014, 10, 55-67. [CrossRef]

24. Kral, M.J.; Ramirez Garcia, J.I.; Aber, M.S.; Masood, N.; Dutta, U.; Todd, N.R. Culture and community psychology: Toward a renewed and reimagined vision. Am. J. Community Psychol. 2011, 47, 46-57. [CrossRef]

25. Kirmayer, L.J.; Malus, M.; Boothroyd, L.J. Suicide attempts among Inuit youth: A community survey of prevalence and risk factors. Acta Psychiatr. Scand. 1996, 94, 8-17. [CrossRef]

26. Dannefer, D. Cumulative Advantage/Disadvantage and the Life Course: Cross-Fertilizing Age and Social Science Theory. J. Gerontol. 2003, 58, 327-337. [CrossRef]

27. O'Rand, A.M. Cumulative advantage theory in life-course research. In Annual Review of Gerontology and Geriatrics: Focus on Economic Outcomes in Later Life; Crystal, S., Shea, D., Eds.; Springer: New York, NY, USA, 2003; pp. 14-30.

28. O'Rand, A.M.; Hamil-Luker, J. Processes of Cumulative Adversity: Childhood Disadvantage and Increased Risk of Heart Attack across the Life Course. J. Gerontol. Soc. Sci. 2005, 60, 117-124. [CrossRef]

29. Schafer, M.; Ferraro, K.; Mustillo, S. Children of Misfortune: Early Adversity and Cumulative Inequality in Perceived Life Trajectories. Am. J. Soc. 2011, 116, 1053-1091. [CrossRef] [PubMed]

30. Séguin, M.; Beauchamp, G.; Robert, M.; DiMambro, M.; Turecki, G. Developmental model of suicide trajectories. Br. J. Psychiatry 2014, 205, 120-126. [CrossRef] [PubMed]

31. Séguin, M.; Renaud, J.; Lesage, A.; Robert, M.; Turecki, G. Youth and young adult suicide: A study of life trajectory. J. Psychiatry Res. 2011, 45, 863-870. [CrossRef] [PubMed]

32. Beaudoin, V.; Séguin, M.; Chawky, N.; Affleck, W.; Chachamovich, E.; Turecki, G. Protective Factors in the Inuit Population of Nunavut: A Comparative Study of people who died by suicide, people who attempted suicide and people who never attempted suicide. Int. J. Environ. Res. Public Health 2018, 15, 144. [CrossRef] [PubMed]

33. Chachamovich, E.; Haggarty, J.; Cargo, M.; Hicks, J.; Kirmayer, L.J.; Turecki, G. A psychological autopsy study of suicide among Inuit in Nunavut: Methodological and ethical considerations, feasibility and acceptability. Int. J. Circumpolar Health 2015, 72, 20078. [CrossRef] 
34. Chachamovich, E.; Kirmayer, L.J.; Haggarty, J.; Cargo, M.; McCormik, R.; Turecki, G. Suicide among Inuit: Results from a large epidemiologically representative follow-back study in Nunavut. Can. J. Psychiatry 2013, 60, 268-275. [CrossRef]

35. Robins, E.; Gassner, S.; Kayes, J.; Wilkinson, R.H.; Murphy, G.E. The communication of suicide intent: A study of 134 consecutive cases of successful (completed) suicide. Am. J. Psychiatry 1959, 115, 724-733. [CrossRef]

36. CIHR Guidelines for Health Research Involving Aboriginal People. Available online: https://cihr-irsc.gc.ca/ e/29134.html (accessed on 26 February 2020).

37. Brown, G.W.; Harris, T.; George, W.; Bifulco, A. Loss of parent in childhood and adult psychiatric disorder: A tentative overall model. Dev. Psychopathol. 1990, 2, 311-328. [CrossRef]

38. Brown, G.W. Contextual measures of life events. In Stressful Life Events and their Contexts; Dohrenwend, B.S., Dohrenwend, B.P., Eds.; Prodist: New York, NY, USA, 1981; pp. 187-200.

39. First, M.B.; Gibbon, M.; Spitzer, R.L.; Williams, J.B.; Benjamin, L.S. Structured Clinical Interview for DSM-IV Axis II Personality Disorders, (SCID-II); American Psychiatric Press: Washington, DC, USA, 1997.

40. First, M.B.; Spitzer, R.L.; Gibbon, M.; Williams, J.B. Structured Clinical Interview for DSM-IV-TR Axis I Disorders, Research Version, Patient Edition. (SCID-I/P); New York State Psychiatric Institute: New York, NY, USA, 2002.

41. Muthen, B.; Masyn, K. Discrete-time survival mixture analysis. J. Educ. Behav. Stat. 2005, 30, $27-58$. [CrossRef]

42. Brezo, J.; Paris, J.; Turecki, G. Personality traits as correlates of suicidal ideation, suicide attempts, and suicide completions: A systematic review. Acta Psychiatr. Scand. 2006, 113, 180-206. [CrossRef]

43. O'Connor, R.C.; Nock, M.K. The psychology of suicidal behaviour. Lancet Psychiatry 2014, 1,73-85. [CrossRef]

44. Grunebaum, M.; Galfalvy, H.; Mortenson, L.; Burke, A.; Oquendo, M.; Mann, J. Attachment and social adjustment: Relationships to suicide attempt and major depressive episode in a prospective study. J. Affect. Disord. 2010, 123, 123-130. [CrossRef] [PubMed]

45. Turner, H.; Finkelhor, D.; Hamby, S.L.; Shattuck, A. Family structure, victimization, and child mental health in a nationally representative sample. Soc. Sci. Med. 2013, 87, 39-51. [CrossRef] [PubMed]

46. Kim, J.; Cicchetti, D. Longitudinal trajectories of self-system processes and depressive symptoms among maltreated and non-maltreated children. Child Dev. 2006, 77, 624-639. [CrossRef] [PubMed]

47. Maniglio, R. The role of child sexual abuse in the etiology of suicide and non-suicidal self-injury. Acta Psychiatr. Scand. 2011, 124, 30-41. [CrossRef] [PubMed]

48. McCrory, E.; Viding, E. The theory of latent vulnerability: Reconceptualising the link between childhood maltreatment and psychiatric disorder. Dev. Psychopathol. 2015, 27, 493-505. [CrossRef]

49. Miller, A.; Esposito-Smythers, C.; Weismoore, J.T.; Renshaw, K.D. The relation between child maltreatment and adolescent suicidal behavior: A systematic review and critical examination of the literature. Clin. Child Fam. Psychol. Rev. 2013, 16, 146-172. [CrossRef]

50. Mironova, P.; Rhodes, A.E.; Bethell, J.M.; Tonmyr, L.; Boyle, M.H.; Wekerle, C.; Leslie, B. Childhood physical abuse and suicide-related behavior: A systematic review. Vulnerable Child. Youth Stud. 2011, 6, 1-7. [CrossRef]

51. Felitti, V.; Anda, R.F.; Nordenberg, D.; Williamson, D.F.; Spitz, A.M.; Edwards, V.; Koss, M.P.; Marks, J.S. Relationship of childhood abuse and Household dysfunction to many of the leading causes of death in adults. Am. J. Prev. Med. 1998, 14, 245-258. [CrossRef]

52. Inuit Tapiriit Kanatami (ITK). National Inuit Strategy on Research2018. Available online: https://www.itk.ca/ wp-content/uploads/2018/04/ITK_NISR-Report_English_low_res.pdf (accessed on 26 February 2020).

(C) 2020 by the authors. Licensee MDPI, Basel, Switzerland. This article is an open access article distributed under the terms and conditions of the Creative Commons Attribution (CC BY) license (http://creativecommons.org/licenses/by/4.0/). 